\title{
Why Do Citizens Vote Against Their Basic Political Values?
}

\author{
LUKAS LAUENER \\ FORS - Swiss Centre of Expertise in the Social Sciences, University of Lausanne
}

\begin{abstract}
The literature on correct and consistent voting has focused on issue-opinions and argument-positions when examining whether vote decisions correspond to individual political preferences. However, the question whether vote decisions align with basic political values has largely been neglected so far. This paper introduces a novel measure named value consistent voting. It finds that, in Switzerland, around $25 \%$ jettison their basic political values when deciding on proposals. Using multilevel regression analysis of survey data, this paper investigates the determinants of value consistent voting. Three theoretical approaches are tested; the sophistication, identification and ambivalence hypotheses. The results show that political sophistication and identification foster value consistent voting. Moreover, there is an interaction between education and adhering to the preferred party's vote recommendation. This finding supports the thesis that highly educated citizens use heuristics most efficiently. However, the more ambivalent people are, the more often they vote against their basic political values.
\end{abstract}

KeYwords: Value consistent voting, direct-democratic decision-making, political core values, popular votes, ambivalence

\section{Introduction $^{1}$}

The well-functioning of a direct democracy requires first and foremost citizens who are willing to participate in political decision-making. Furthermore, citizens should have sufficient information about the policy proposals at stake, which ideally allows them to opt for their preferred answer when voting. For Habermas (1983), essential components of an ideal democracy are met, if individuals take part in the deliberation process voluntarily and without outer manipulation, if they acquire sufficient knowledge for their decision and if they are capable of expressing their will at the ballot box freely and in accordance with their distinct beliefs and preferences. The same holds true for Dahl (1989), who names effective participation and enlightened understanding as two of the most important criteria for a good democracy. Both, participation and information are indispensable prerequisites for direct-democratic systems.

\footnotetext{
${ }^{1}$ I would like to thank Céline Colombo, Silja Häusermann, Simon Lanz, Gian-Andrea Monsch, the two anonymous reviewers and the editors for their insightful and valuable comments on earlier versions of this article. Many thanks for their helpful suggestions and remarks also go to the participants of the panel on voting behaviour at the 2018 Annual Conference of the Swiss Political Science Association and to the participants of the GREC («Groupe de Recherche sur les Élections et la Citoyenneté Politique») seminars at the University of Lausanne / FORS.
} 
Hence, the quality of direct-democratic decisions can be assessed by two questions, namely whether citizens participate in popular votes and, for those who do so, whether they vote in line with their true political preferences. Switzerland's highly developed directdemocratic system allows for an empiric evaluation of these two factors. Between 1848 and 2013, more than half of all nation-wide popular votes took place in this country (Milic et al. 2014). However, turnout in popular votes is generally low in Switzerland. In 2018, only $43.7 \%$ of all eligible voters participated (BFS 2018). Similar democratic deficits as in the case of simple abstention arise, when citizens who do actually participate remain incapable of expressing their true preferences at the ballot box.

This paper builds on the literature on correct and consistent voting. Previous studies have mainly used argument-based methods in order to shed light on the question whether individuals vote according to their political preferences (e.g., Lanz and Nai 2015; Milic 2012). In this paper, I propose a novel measure of consistent voting that focuses on political core values ${ }^{2}$ and shall be named value consistent voting. I argue that next to argument-based methods of correct voting, value consistent voting is an important and often neglected dimension of voting behaviour. Political core values are more stable and less vulnerable to the impact of current events than political arguments or opinions. In theory, they are also more comprehensive because they underlie political arguments and opinions. Moreover, values are supposed to reflect fundamental understandings of the good society. Direct-democratic voting on policy proposals is arguably seen as the vehicle that allows citizens to express those understandings. The contribution of this article is twofold. First, it makes a methodological contribution by introducing a novel measure of consistent voting behaviour. Second, it expands on the literature on correct and consistent voting by taking into account and emphasising the ideological coherence of political decisions. The article tries to solve the puzzle why citizens vote against their basic political values in a direct-democratic system that theoretically allows them to pursue their individual beliefs and core values.

\section{From Correct to Consistent Voting}

Voting in line with one's preferences and attitudes is commonly referred to as correct voting. Comprehensive literature on correct voting is particularly found in the United States. Lau and Redlawsk (1997: 586) define a correct vote decision as "one that is the same as the choice which would have been made under conditions of full information». The authors compute that around $75 \%$ of the American electorate are capable of coming to a vote decision that corresponds to their own preferences (Lau and Redlawsk 1997).

In Switzerland, too, there is a wide range of literature on correct voting (Milic 2008, 2010, 2012; Milic et al. 2014; Nai 2009, 2015). In his study, Milic (2012) introduces an argument-based method to measure whether voters come to an «objectively correct» decision. Based on individual acceptance levels of arguments in favour of or against specific proposals, he computes argument-positions for respondents of post-vote surveys. These argument-positions allow for a hypothetical vote decision towards which the respondent should theoretically lean. By comparing argument-position and actual decision, Milic (2012) reasons whether an individual voted correctly. For Nai (2015) on the other hand, the comparison between uninformed and informed voters is primordial in establishing the «correctness» of a vote decision. In his reasoning, a decision of an

\footnotetext{
${ }^{2}$ I use the terms political core values and basic political values interchangeably in this paper.
} 
uninformed voter is correct when it is congruent with the decision made by a clear majority $^{3}$ of the most informed citizens that have identical ideological profiles as the uninformed person. In their study, Lanz and Nai (2015) introduce the alternative term of consistent voting. They define a vote decision as consistent if «it is in line with the voter's position on the issue at stake and hence reflects her opinion on the principal issue-related arguments» (Lanz and Nai 2015: 121) and consider their definition as a subset of correct decisions.

\section{What About Ideological Coherence of Vote Decisions?}

The before-mentioned studies fall short of a measure that tells us whether individuals vote in line with their own political core values. According to Lau and Redlawsk (1997: 586), a definition of what a correct decision is should be based «on the values and beliefs of the individual voter, not on any particular ideology that presumes the values and preferences which ought to be held by members of different social classes, for instance, and not on any larger social goods or universal values». This article does neither claim to refine nor redefine the measure of correct voting but rather expands it by investigating the dimension of value consistency in vote decisions. Following the political belief system literature, Sabatier and Weible (2007: 194ff) conceptually distinguish between core beliefs and secondary beliefs. They argue that core beliefs are wider in scope, more stable over time and very difficult to change compared to secondary beliefs (Sabatier and Weible 2017: 194196). This conceptualisation can be applied to describe differences between political core values and political arguments or opinions. Accordingly, basic political values are more stable and less vulnerable to the impact of current events than political arguments or opinions. Furthermore, the Michigan model identifies various factors that influence a person's vote choice and build a «funnel of causality». In this «funnel of causality», basic value orientations form long-term political preferences and thus underlie issue opinions that are less stable (Campbell et al. 1960). Therefore, I argue that basic political values are at least as important as political arguments and opinions to be looked at when examining the quality of vote decisions.

The literature discusses an important shortfall of argument-based methods to measure the «correctness» of a vote decision (cf. Lanz and Nai 2015; Nai 2015 for an extensive discussion). Namely, the post-vote survey data used lacks information about the relevance and importance that individual respondents ascribe to specific arguments. Rather, they indicate to what extent proposed arguments for and against proposals encounter their personal acceptance or refusal. The assumption that all arguments are equally important to citizens is not a realistic one. For instance, a citizen might consider all arguments in favour of a popular initiative as valid. Nonetheless, she votes against it because of one specific counterargument that is crucial to her.

When examining whether a vote decision is coherent with basic political values, a similar problem arises. We do not know which value dimension plays the most important role in deciding on how to vote on a specific proposal. In fact, several competing political core values might influence individual choices. In this paper, I try to avoid this situation by choosing proposals that are clearly attributable to specific value dimensions and analysing only voters that have a clear stance regarding questions on basic political values

\footnotetext{
${ }^{3}$ Nai (2015) uses a threshold of $60 \%$ to define a clear majority. While acknowledging that this choice is rather arbitrary, he argues that the threshold was decided out of «pragmatic and empirical reasons».
} 
(see chapter «Data, Operationalisation and Method»). Nevertheless, this does not necessarily mean that the identified «main» value cleavage was crucial for all voters when deciding on the proposal at hand. Since this paper does not measure correct voting but whether citizens' behaviour at the ballot boxes aligns with their basic political values, I argue that the problem of not knowing about the prevalence and importance individuals ascribe to basic political values is somehow mitigated.

To define basic political values, I rely on the conceptual definition of values by Schwartz and Bilsky (1987). This definition incorporates five features that are recurrently mentioned in the literature: Values (1) are concepts or beliefs, (2) pertain to desirable end states or behaviours, (3) transcend specific situations, (4) guide selection or evaluation of behaviour and events, and (5) are ordered by relative importance (Schwartz and Bilsky 1987: 551). Because of the greater stability of political core values and their subordinate role that they have played in the literature on correct and consistent voting so far, this article introduces the concept of value consistent voting which deliberately focuses on the question whether citizens stick to their political core values when deciding on vote proposals.

\section{Drivers of Correct and Consistent Voting}

In order to elaborate a theoretical framework and come up with possible determinants of value consistent voting, this article builds on findings in the literature on correct and consistent voting that shall be briefly reviewed in the following lines.

In laboratory experiments, Lau and Redlawsk (1997, 2006) investigate differences in voting behaviour of participants with diverging levels of information about candidates and show that rates of correct voting increase, as participants possess more information about them. By all means, it is also possible that uninformed voters come to a vote decision that reflects their political preferences. Lupia (1994) finds evidence that mental shortcuts, socalled heuristics, enable uninformed citizens to imitate decisions of the better informed and still vote in line with their political beliefs. Preferences and opinions of family members, friends, colleagues, political parties, associations as well as recommendations of the government or the parliament are examples of heuristics (Lupia 1994). The mere availability of heuristics already positively correlates with a correct vote decision (Lau et al. 2008; Milic 2012). Another study demonstrates that heuristics only lead to a higher probability of correct voting when those who use them are politically interested (Lau and Redlawsk 2001). The effect is, however, contrary for people who are not interested in politics.

Political interest and knowledge are generally among the strongest determinants of a correct or consistent vote decision (Lanz and Nai 2015; Lau and Redlawsk 2001, 2006, 2015; Lau et al. 2008; Nai 2015). Affiliation to social networks is another key determinant that facilitates a decision in line with personal preferences (Sokhey and McClurg 2012). Even personality traits have significant effects on correct voting. For instance, calm, emotionally stable, curious and open-minded people exhibit a significantly higher probability to vote correctly than their counterparts do (Ha and Lau 2015).

On the contextual level, a high intensity of the political campaign is overall a good predictor of correct or consistent voting (Lanz and Nai 2015; Lau et al. 2008; Milic 2012). Nai (2015) finds that, during intensive political campaigns, the probability of casting a correct vote decreases when negative messages towards a proposal outbalance positive ones. Strong programmatic differences between candidates who are running for office enhance the probability of a correct vote decision (Lau et al. 2008). In a cross-national study, Lau et al. (2014) illustrate that the probability to elect candidates who correspond 
to own political preferences decreases as the number of competing parties and candidates increases. High numbers of competing parties and candidates mean that citizens have to invest more time in looking for information and assessing them in order to make an informed decision (Lau et al. 2014). This obviously complicates the decision-making process and leads to a smaller probability of a correct vote decision (Lau et al. 2014). Milic's (2012) study suggests that the share of people who vote correctly is affected by the complexity of the proposal, the familiarity with the subject, the availability and visibility of mental shortcuts, the number of proposals at stake on the same day and the general conflict pattern. The one-sidedness of political campaigns has been identified as yet another influential variable on the contextual level: The greater the dominance of a party, association or union, the higher is the probability that citizens vote against their true preferences (Bergbower et al. 2015; Holbrook and McClurg 2006).

\section{Theories and Hypotheses of Value Consistent Voting}

Theories of opinion formation highlight the importance of political sophistication, skills and identification in individual decision-making. Over the past two decades, there has been a shift to more eclectic dual models of opinion formation processes (Rosenberg 2015). Thereby, generally two types of processes are distinguished. The first type includes «central» processes that are relatively demanding. In order for citizens to form an opinion on a political matter, they have to evaluate relevant information and arguments. Therefore, they need a certain level of political sophistication. So-called «peripheral» processes, on the other hand, are less demanding. They include classical conditioned responses to political problems. These responses are often evoked by the individual's identification with a specific social group or political party and reliance on their information cues (e.g., use of party heuristics). Contemporary work indicates that group identification powerfully influences citizens' opinion formation (cf. Rosenberg 2015).

Furthermore, individual political preferences play another important role in theories of opinion formation. Zaller finds that most citizens do not have «just one attitude» towards political questions (1992: 54). «Rather than endorsing one side of a political debate and refuting the other, individuals often embrace central elements of both sides» as Lavine (2001: 915) appropriately describes the phenomenon of ambivalence. This article elaborates on the aspect of political preferences by examining to what extent they influence value coherence in vote decisions when they aim into the same direction or contradict each other. In this paper, I develop and test the «sophistication hypothesis», the «identification hypothesis» and the «ambivalence hypothesis».

\section{Sophistication Hypothesis (H1)}

According to Zaller (1992), receptiveness for political information as well as its consistent placement within the own individual value scheme increase with higher levels of political sophistication. The level of education serves as one of the most important and most suitable predictor of a person's political sophistication (e.g., Converse 1964; Delli Carpini and Keeter 1996; Jerit et al. 2006). To wit, people with higher educational achievements generally dispose of more cognitive resources which allow them to deal with the vote project at hand more systematically and to ultimately make a decision that is in line with their own values. A higher educational background should thus enhance the probability of value consistent voting. 
Political interest can be regarded as motivation of political participation as it leads to a higher probability of getting involved in democratic decision-making processes (Hadjar and Becker 2006). According to Bühlmann and Freitag (2006), politically interested and motivated citizens gain a deeper understanding of proposals. Those people who are politically interested and acquire a profound understanding of the proposal at hand should tend to vote in line with their political core values more often.

Hypothesis 1.1: The higher the education level of a person, the higher the probability of casting a value consistent vote.

Hypothesis 1.2: The higher a person's level of proposal specific knowledge, the higher the probability of casting a value consistent vote.

Hypothesis 1.3: The higher the political interest of a person, the higher the probability of casting a value consistent vote.

\section{Identification Hypothesis ( $\mathrm{H} 2$ )}

As an alternative explanatory approach, I examine the influence of group identities, which play various roles in direct-democratic decision-making. Several studies conclude that high levels of social integration and interaction foster an individual's willingness to participate in political decision-making processes as well as his knowledge about them (Campbell et al. 1960; Key 1952; Verba and Nie 1972; Verba et al. 1978). Members of political parties, associations, unions, or sports clubs or people who get involved with these groups reach high levels of social integration and interaction. Due to their dense social network, these people participate in democratic decision-making more regularly and know more about political questions at stake. Regular interactions and discussions with like-minded fellow citizens allow for exchanging ideas and forming opinions more easily. This paper tests the question whether identification with a political party and endorsement of vote recommendations result in value consistent vote decisions. Voters who identify with a political party are presumably more often surrounded by like-minded fellow citizens than their respective counterparts. This allows them to discuss political questions in more detail, to put vote proposals into a larger context and to better link them to their basic political values. These interactions help party sympathisers to reveal their own political core values and associate them to the proposal at hand. They should thus tend to vote more often in line with their basic political values. I assume that voters who do not only identify with a political party but also endorse the recommendation made by their preferred party exhibit a greater degree of interaction and identification with the party than those who do not follow its vote recommendation. ${ }^{4}$ Likewise, it can be postulated that the former group votes more value consistently than the latter one.

\footnotetext{
${ }^{4}$ In the post-vote survey data used for this study, we do not know if voters who identify with a political party and endorse its vote recommendation actually do so consciously. It is impossible to derive whether they used their preferred party's recommendation as a mental shortcut to reach their decision. I assume though, that many people who sympathise with a political party at least consider its vote recommendation at an earlier or later stage in their decision-making process. It remains however unclear what weight they attribute to the party's recommendation in their decision.
} 
Hypothesis 2.1: Individuals who identify with a political party have a higher probability to cast a value consistent vote than those who do not identify with a political party.

Hypothesis 2.2: Individuals who identify with a political party and follow its vote recommendation have a higher probability to cast a value consistent vote than those who do not follow its vote recommendation.

Group identities can enable less informed citizens to reach a correct decision, for example when they make use of mental shortcuts, so-called heuristics, such as vote recommendations (Lupia 1994). In the literature, it is contested whether heuristics enable everyone equally well to come to a decision that reflects basic values and preferences. To wit, it has been demonstrated that precisely those people who least depend on mental shortcuts use them most efficiently (e.g., Lau and Redlawsk 1997, 2001; Sniderman et al. 1991). Citizens with low levels of political sophistication use heuristics, too. However, they are less capable of applying them in a way that their vote decision corresponds to their actual political attitudes and preferences in the end.

In order to test whether the effect of corresponding to vote recommendations on value consistency is moderated by education, I introduce an interaction hypothesis. In line with the literature on heuristics, only highly educated people are assumed to benefit from party cues, which should result in a higher probability of value consistent voting for them. For people with lower education, the effect of voting in line with their preferred party on value consistent voting should be smaller or even disappear. To test whether the interaction hypothesis holds true, I firstly need to identify if there is a difference in outcomes for value consistency between those who identify with a political party and adhere to its vote recommendation on the one hand and party sympathisers who do not correspond to the recommendation on the other hand. This is done in hypothesis 2.2. By introducing education as a moderating variable, I secondly reveal if corresponding to the preferred party's recommendation yields different effects on value consistent voting across varying levels of education. The results shed some light on the question whether all voters are equally capable of coming to a value consistent vote decision when following their preferred party's recommendation. ${ }^{5}$

Interaction hypothesis 2.3: With increasing levels of education, people who identify with a political party and follow its vote recommendation have a higher probability to cast a value consistent vote than those who do not follow its vote recommendation.

\section{Ambivalence Hypothesis (H3)}

Milic (2012) finds that only a very small proportion of the electorate does not have an ambivalent stance on vote proposals. This finding ties in well with Lavine's (2001) that

\footnotetext{
5 A number of other interaction hypotheses is theoretically conceivable. For instance, the familiarity or salience of the issue might moderate the effect of following a party recommendation on value consistent voting. Arguably, party sympathisers who «blindly» endorse their party's recommendation are more likely to vote value consistently but only if the proposal issue is salient or familiar to them. In these cases, it is more likely that the value preferences of the voter and her preferred party are congruent. On the other hand, following party recommendations on proposals that are not familiar or salient to the voter presumably leads to a higher chance of a value inconsistent decision. Unfortunately, there is no appropriate measure of individual issue familiarity or salience in the data used for this article, which is why this interaction hypothesis could not be tested.
} 
individuals often support arguments of both political camps opposing each other. Some literature has identified detrimental effects of ambivalence on individual voting behaviour (e.g., Basinger and Lavine 2005; Lavine 2001; McGraw et al. 2003). Accordingly, «ambivalence creates instability in candidate evaluations, substantially delays the formation of citizens' voting intentions, diminishes the influence of both personality assessments and issue proximity on summary candidate evaluation, and ultimately weakens the prediction of vote choice» (Lavine 2001: 916). Lavine et al. (2012) find that in the U.S. presidential elections, ambivalent voters orient themselves towards issues, i.e. questions regarding campaign contents, rather than ideology. Contrary to the literature on the detrimental effects of ambivalence, the authors argue that ambivalent citizens are not «inferior» voters who are incapable of taking decisions. Thanks to their highly ambivalent position, these people deal with alternatives more systematically. Compared to their univalent fellow citizens, ambivalent people achieve a higher level of knowledge about the issues concerned and ultimately, being extremely well informed, come to high quality decisions (Lavine et al. 2012). But do these decisions also reflect voters' basic political values?

In order to test the relationship between ambivalence and value consistency in vote decisions, I specify in the following what ambivalence theoretically means and how the concept is captured empirically. ${ }^{6}$ In this study, the definition of ambivalence is based on individual argument-positions concerning the proposal at hand. Ambivalent voters are those people that support arguments from both political camps, i.e. the pro- and the contra-side. They exhibit a certain level of ambivalence in their decision-making process as they hover between a «yes» and a «no» vote. Obviously, the level of ambivalence towards a proposal varies from person to person. Voters who support arguments from the proand the contra-side to the exact same degree are those with the highest level of argumentbased ambivalence towards the proposal. I thus call them highly ambivalent voters. As long as voters accept arguments from both political camps, they are somewhat ambivalent towards the proposal. Their level of ambivalence is defined by the question of how far their acceptance of pro-arguments diverges from their acceptance of contra-arguments. The more firmly voters support arguments of one side and - at the same time disapprove arguments of the other side, the more their level of ambivalence declines. Voters who support every single argument in favour of the proposal and reject all arguments from the opposite side (or vice versa) are univalent, i.e. they have no argumentbased ambivalence towards the proposal whatsoever.

In summary, the theoretical concept of ambivalence applied in this article thus depends on issue-positions regarding different arguments in favour of or against vote proposals. Hence, ambivalent voters are not ambivalent because of their political value orientations but because of their contradictory positioning on specific argument questions concerning the vote proposal. The restriction on such an argument-based ambivalence is due to the research design of this study: In order to investigate value consistency in vote decisions, I had to exclude voters with unclear or unreported political value preferences, i.e. only voters with clear value preferences are being analysed. ${ }^{7}$

As described earlier, the theoretical model of the «funnel of causality» argues that basic value orientations form long-term political preferences that then transfer into issue opinions,

\footnotetext{
${ }^{6}$ For a comprehensive theoretical overview and empirical findings on the question under which individual and contextual conditions citizens have higher chances to encounter ambivalence, see Nai (2014).

${ }^{7}$ See chapter «Data, Operationalisation and Method» for more details on the case selection and study set-up.
} 
including opinions on concrete political arguments (Campbell et al. 1960). Therefore, there is an important interdependence between argument-positions that I use to define the level of ambivalence and basic value preferences. For a large majority of voters (70\%), individual argument-positions are inferable when knowing about their basic value orientations. This means that in these cases, basic value orientations predetermine the voter's overall positive or negative argument-based stance towards the vote proposal. Descriptive analyses show that voters, for which the overall argument-position is not inferable from their value preferences, are more susceptible to vote against their basic political values. ${ }^{8}$ For the empirical analyses in this article, it is not crucial whether the individual argument-positions add up to a less or more favourable stance towards the proposal at hand nor whether value preferences influence this overall argument-position. The ambivalence hypothesis rather focuses on the question to what degree individual argument-positions are contradicting and how argument-based ambivalence influences value consistent voting behaviour.

Basing the theoretical concept of ambivalence on argument-positions, one could argue that certain individuals are perfectly capable of integrating competing considerations into a value consistent position, whereas others might indeed become ambivalent towards a vote proposal. This raises the question whether we are truly dealing with ambivalent voters when they support arguments from both political camps. Out of two reasons, I would argue that competing stances on arguments from both political sides are - up to a certain degree - linked to ambivalence. First, those citizens with the most competing stances, i.e. the highly ambivalent citizens in this study, generally find it more difficult to make up their minds on a vote proposal than less ambivalent and univalent people. ${ }^{9}$ Second, the first group also takes considerably more time to nail down their position and come a vote decision. $^{10}$

How does ambivalence influence value consistent voting? I anticipate a U-shaped correlation between ambivalence and value consistency in vote decision as depicted in Figure 1.

When deciding on how to vote, univalent citizens are presumably guided by their basic political values to a large extent and align their argument-positions most likely according to them. Voters on the other side of the ambivalence spectrum, i.e. highly ambivalent citizens, probably come to their vote decision only after due consideration and systematic examination of the proposal at hand. For these people, I also expect the final decision to be in line with their basic political values. Basic political values can serve as a useful guideline for highly ambivalent voters who find themselves in a seemingly irresolvable

\footnotetext{
${ }^{8}$ These are voters whose value preferences and argument-positions do either not align (23\% of all voters) or for which one cannot draw any conclusion about whether they align or not because they have an overall neutral argument-position $(6 \%)$, i.e. they support pro- and contra-arguments of the proposal to the exact same degree.

${ }^{9}$ Only $11 \%$ of univalent voters (i.e. the group without any contradictory stances on argument questions regarding the vote proposal) reported that they had difficulties when forming their opinion on the proposal. People in the middle category, which incorporates those with varying degrees of competing stances on arguments, had more difficulties when forming their opinion $(20 \%)$. The percentage of people reporting suchlike difficulties was the highest among highly ambivalent voters $(30 \%)$.

${ }^{10}$ Compared to univalent citizens $(6 \%)$, more than twice as many highly ambivalent voters indicated having taken their decision within the last few days before the vote took place (13\%). With $9 \%$ having taken their decision just a few days before the vote, the middle category lies in between the two extremes. $58 \%$ of univalent voters further reported that their decision had «always been clear from the beginning». This was the case for $45 \%$ of people with varying levels of ambivalence, while only $39 \%$ of the highly ambivalent voters stated that they had always known how to decide on the proposal.
} 
Figure 1: Hypothesised Relationship between Ambivalence and Value Consistent Voting

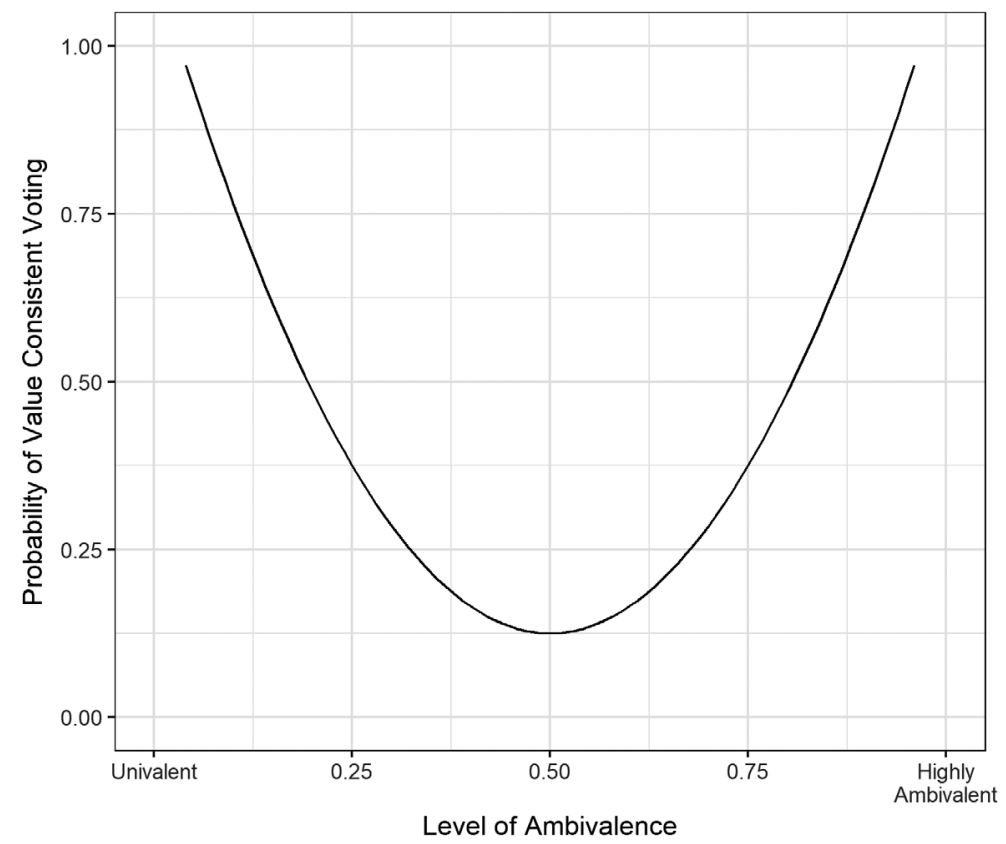

dilemma. For voters with average levels of ambivalence, it is likely that one specific argument prevails or an external influence constitutes the crucial point in their decisionmaking process. Compared to univalent and highly ambivalent voters, they should thus tend to come to value consistent vote decisions less often.

Hypothesis 3: There is a U-shaped correlation between the level of ambivalence and value consistency in vote decisions. Univalent and highly ambivalent people have a higher probability of casting a value consistent vote than people with average levels of ambivalence.

\section{Data, Operationalisation and Method}

Since 1977, opinion surveys are carried out after each federal vote in Switzerland. These post-vote surveys are conducted among a randomly selected representative sample of around 1000 to 1500 eligible voters across all language regions and cantons. They mainly focus on citizens' interest, motivation and knowledge regarding the most recent popular vote and politics in general. From 1977 to 2016, these surveys were called VOX; since 2016 they are named VOTO. For this study, I use a pooled data set made up by VOX surveys on specifically selected votes (Kriesi et al. 2017). Some variables indicating contextual-level characteristics were added from an aggregated VOX data set. ${ }^{11}$

\footnotetext{
${ }^{11}$ The aggregated VOX data set stems from Hanspeter Kriesi, professor of political science at the European University Institute (EUI) in Florence. For the four most recent votes in the data set, missing data about newspaper articles have been completed thanks to information made available by Année Politique Suisse (APS 2015, 2016; Bernhard 2014, 2015).
} 
To select the vote items for the pooled data set in the first place, this paper relies on correlation analysis between vote decisions and political value dimensions. ${ }^{12}$ VOX questionnaires contain several basic political values that fit well into the conceptual definition by Schwartz and Bilsky (1987) and on which respondents are asked to express their views. These include, for instance, the questions whether environmental protection or economic prosperity is more important, whether citizens prefer state interventions in the economy or a free market, or whether Switzerland needs a strong army or none at all. As a basic criterion for selecting the vote proposals, they need to be clearly attributable to one or - in some cases - two value dimensions. In order to have a variety of different political core values, I chose the following six value dimensions which stand for major political conflicts in the Swiss society: «strong versus no army», «high versus no income disparities», «equal opportunities for foreigners and Swiss citizens versus better chances for the Swiss», «environment versus economy», «free market versus regulation», and «open versus isolated Switzerland». VOX surveys in which respondents were asked to position themselves on the first five value dimensions cover a total of 206 vote proposals between 1993 and 2016. The question on the sixth value dimension, «open versus isolated Switzerland», was part of VOX surveys covering 178 proposals between 1996 and 2016. I conducted correlation analysis across all these proposals and identified, for each of the six value dimensions, five proposals for which individual vote decisions most closely matched attitudes expressed along the respective value dimension. The minimal acceptable threshold was set to an absolute correlation value of $0.3 .^{13}$ This procedure adds up to a total of 30 vote items in the pooled data set of which 27 are unique ones. ${ }^{14}$ These include, for example, the popular initiative «For a credible security policy and a Switzerland without army» that strongly correlates with the value dimension "strong versus no army» or the optional referendum on the approval of the sectoral treaties between the Swiss Confederation and the European Community that strongly correlates with the dimension «open versus isolated Switzerland».

\footnotetext{
${ }^{12}$ I use the Point-Biserial Correlation Coefficient to measure correlation. This coefficient is applied when measuring the strength of the relationship between a dichotomous variable (in this case: vote decision) and a continuous variable (placement on value dimension) (Chen and Popovich 2002). Mathematically, the PointBiserial Correlation Coefficient is computed in the same way as the Pearson's Correlation Coefficient (Chen and Popovich 2002). The computed values of the correlation coefficient vary between -1 and +1 , whereby values around \pm 1 are said to reflect a perfect degree of association between the underlying two variables. The smaller the absolute value, the weaker is the relationship between the two variables.

${ }^{13}$ In social science research, it is commonly agreed upon the fact that there is no linear relationship between two variables below this threshold. In some cases, high correlations between vote decisions and citizens' placements on the respective value dimension were also found for vote items that have nothing to do with attitudes along the value dimension in question. For example, the popular initiative «40 military training areas are enough» yields a strong correlation with attitudes along the value dimension «high vs. no income disparities». After analysing the contents of possible «intruder» proposals in detail and evaluating whether they are indeed not linked to the value dimension in question, some proposals were excluded from analysis and do not figure in the data set despite of their high correlation values.

${ }^{14}$ See Table A1 in the Online Appendix for the vote proposals included in the pooled data set.
} 
For subsequent analysis, I only use respondents who meet the following conditions. They need to have participated in the vote and either voted «yes» or «no». ${ }^{15}$ Furthermore, they must have a clear stance on the respective political value dimension that can be compared to their vote decision. This means that respondents who only have a vague stance towards the political core value in question, who refuse to reveal their stance or simply say «I don't know» are excluded from the sample. A total of 13'338 individual observations apply to these restrictions and are taken into account for the regression analysis.

Now, one could argue that this procedure represents a substantial reduction from the 206 initial vote proposals for which data on positions along value dimensions was available to just 27 that constitute the pooled data set and for which value consistent voting behaviour is studied. Is there not a serious selection bias involved in this procedure? In order to study value consistency of vote decisions, I chose the above-mentioned variety of political core values. Depending on the value dimension, the vote proposals yield different correlation scores ranging in absolute values from 0.33 to 0.98 (see Table A1 in the Online Appendix). Hence, the proposals in the data set vary with regard to the correlation between individual vote decisions and positions on the respective value dimension. The fact that six different value dimensions are considered allows for a certain variety in value consistency across proposals. This means that overall, i.e. across the six value dimensions, I did not only choose proposals where one could expect the most value consistency. However and admittedly, this is the case when looking at each value dimension separately. Within each value dimension, I chose five proposals for which vote decisions correlated the most with positions on the respective political core values. Hence, there is a selection bias within but not across the different value dimensions.

In order to reduce the selection bias within each value dimension, one could enlarge the pooled data set and also include proposals with lower correlation values between vote decisions and value preferences. However, such an enlargement would pose a theoretical problem: As described above, the basic selection criterion for proposals to be chosen is that they need to be clearly attributable to a value dimension. If one were to increase the number of proposals in the analysis (or in the extreme case include all of them), it would be more difficult or even impossible to attribute proposals with low correlation values to a value dimension. Hence, the theoretical construct of value consistent voting could not be tested anymore since the data set would include a high number of proposals for which vote decisions and value preferences would have nothing to do together. Identifying the relevant underlying value dimension against which vote decisions should be tested would then become an arbitrary choice that would need to be justified theoretically on a case to case basis. The same problem would arise, if one were to lower the threshold of the

\footnotetext{
${ }^{15}$ Respondents stating that they did not participate in the vote are excluded from regression analysis. The same applies to those who casted a blank vote, who did not remember what decision they came to or who were not willing to answer the interviewer's question regarding their personal vote decision. It could be argued that citizens casting a blank vote are those who cannot decide between the two options, hence the most ambivalent ones. However, we do not know anything about these citizens' motivational backgrounds to cast a blank vote. More precisely, we do not know if they cast a blank vote because they are in fact ambivalent or because of other reasons such as lacking political interest, high complexity of the vote item, some sort of protest behaviour, etc. Furthermore, a problem regarding the coding of value consistent vote decisions would ultimately arise. Since we do not conclusively know what triggers an individual's decision to cast a blank vote, evaluating its value consistency with underlying political values would be imprudent.
} 


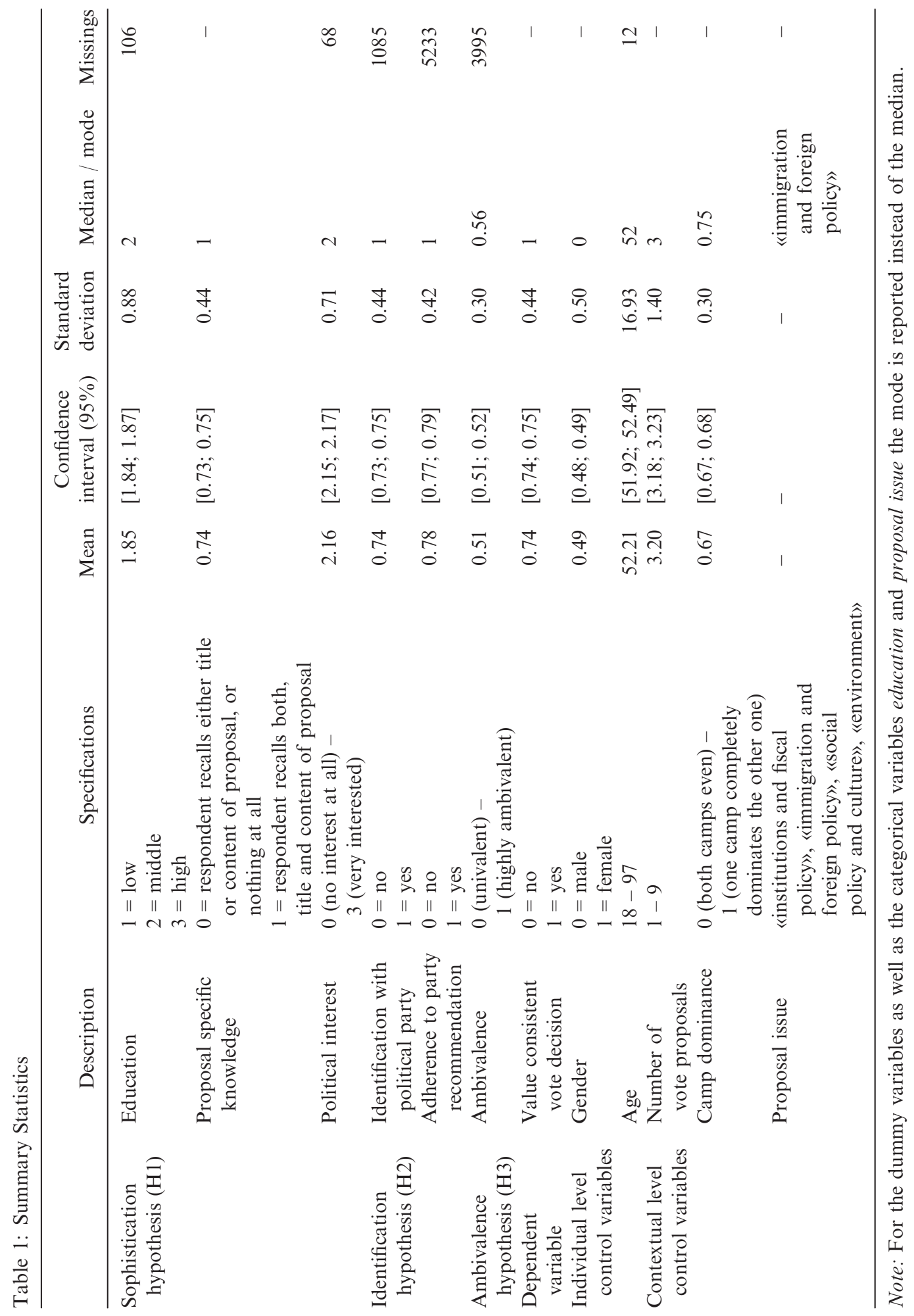


correlation coefficient and include proposals for which an underlying value dimension cannot be identified.

I would thus argue that restricting the sample size by applying correlation analysis that exogenously defines the relevant proposals for analysis, setting a clear cut-off value and removing all respondents with unclear stances on the value dimensions in question from the analysis best serve the purpose of answering the research question of this article. What drives voters who have a clear position on political core values to differ from it when deciding on vote proposals?

\section{Independent, Dependent and Control Variables}

Table 1 reports the summary statistics of all independent variables, the dependent variable «value consistent vote decision» as well as the control variables whose construction is described in the following.

The theoretical assumptions made in the sophistication hypothesis (H1) are operationalised using voters' level of education, proposal specific knowledge and political interest. The variable education originally contained six categories ${ }^{16}$ that were subsumed into a low, middle and high level of education for subsequent analyses. Regarding the variable indicating a person's knowledge about the proposal at hand, respondents who recall both, title and content of the proposal, are defined as having a high level of proposal specific knowledge (1). The value 0 is attributed to people who only memorise either the title or the content of the vote item or nothing at all. These people have a low level of proposal specific knowledge. Political interest ranges from 0 to 3 with the lowest value meaning no political interest whatsoever and the highest one meaning that the respondent is very interested in politics. ${ }^{17}$

I use the independent dummy variables identification with political party and adherence to party recommendation to check the validity of the identification hypothesis $(\mathrm{H} 2)$. Voters who identify with a political party are attributed the value 1 for party identification, those who do not receive a 0 . In order to compute the variable adherence to party recommendation, I only take into consideration those respondents who identify with a political party. In case they stick to their preferred party's vote recommendation when deciding on the proposal they receive the value 1, while those who differ from the recommendation are coded as 0 .

The testing of the ambivalence hypothesis (H3) requires a translation of opinions on arguments regarding the specific proposals into an ambivalence index for each person (cf. procedures used in Frey 2015; Milic 2012; Nai 2015). This index ranges from 0 to 1 whereas the minimum stands for univalent voters and the maximum represents voters that are highly ambivalent towards a proposal. ${ }^{18}$

The dependent variable value consistent vote decision describes whether an individual has voted in line with her basic political values. This variable is dichotomous with 0 indicating

\footnotetext{
${ }^{16}$ The original VOX question asks for the highest educational attainment and distinguishes the following six categories: 1 = compulsory schooling; 2 = apprenticeship; 3 = Upper Secondary School, University of Teacher's Education; 4 = higher professional training; 5 = higher specialist colleges; $6=$ university, Federal Institute of Technology, University of Applied Sciences

${ }^{17}$ In the regression models, I treat political interest as a continuous variable in order to simplify the interpretation of the outcomes. The assumption which then applies, namely that all one-unit increases between the different levels of political interest are equal, can of course theoretically be contested.

${ }^{18}$ See Online Appendix for the computation of the ambivalence index.
} 
an inconsistent and 1 a consistent vote decision. It is computed by comparing citizens' individual placements on the relevant political value dimension to their vote decision. ${ }^{19}$ In the sample used for this study, $25.6 \%$ casted a value inconsistent vote. ${ }^{20}$

The control variables on the individual level include gender and age. On the contextual level of analysis, I control for a few factors that have theoretically and practically proven to be of some significance in the literature on correct and consistent voting. They might thus also add something to the explanation why people vote according to their basic political values. First, a high number of proposals on the same day presumably has a negative effect on value consistent voting. According to the theory of bounded rationality (Simon 1957), citizens only dispose of limited time and financial resources to obtain comprehensive information about the proposals at hand. With an increase in the number of proposals, time becomes scarce for voters to read up on all proposals equally well, why they might less often align their final decision with their political core values or do so in a less proper way. The number of vote proposals is simply a count of proposals that citizens had to decide on simultaneously on the same voting date.

Second, in political campaigns resources are often unequally distributed between supporters and opponents of proposals. A strong visible dominance of either political camp means for example that it can place more advertisements in newspapers or send out more speakers to public events. As a result, the population only receives partial and biased information. Since voters are never capable of informing themselves about every single aspect of a proposal, they rely on the limited information that is available for their decision-making. When people are confronted with only one (biased) interpretation of a political question, they often tend to adopt this interpretation - regardless of their general political beliefs but only when this interpretation seems mostly acceptable to them (Lau et al. 1991). In cases where campaign information contains multiple diverging interpretations of the question at stake, contextual information such as information about supporters and opponents of the proposal or about the political elite discourse becomes more prominent in the decision-making process pushing individuals to align the different interpretations with their basic political values (Zaller 1992). Clear dominances of either political camp should result in a greater share of people who vote value inconsistently. Camp dominance is measured using the number of advertisements that supporters and opponents of the proposal put into newspapers. The computed index's minimum of 0 means that both political camps were evenly represented during the campaign whereas the maximum of 1 indicates a situation in which one political camp completely dominated the other one. $^{21}$

Finally, citizens might be prone to vote in line with their basic political values depending on the topic of the vote proposal. Some issues are more familiar to them, easier

\footnotetext{
${ }^{19}$ See Online Appendix for an example of how the dependent variable value consistent vote decision is operationalised in detail.

${ }^{20}$ Note that studies on correct voting found similar numbers of people who did not come to a correct decision according to the respective definition used (cf. Lau and Redlawsk 1997, 2006; Lau et al. 2008; Nai 2015; Sokhey and McClurg 2012). For example, Lau and Redlawsk (1997) found that $25 \%$ of the American electorate are incapable of making a vote decision that corresponds to their own preferences. Nai (2015) reported that, among citizens with incomplete information, $36.7 \%$ did not cast a correct vote. Since the two concepts of correct and value consistent voting theoretically diverge from each other to a large extent, a direct comparison of these percentages is not meaningful.

${ }^{21}$ More information about the camp dominance index as well as an example of its computation can be found in the Online Appendix.
} 
to understand, more often in the media or closer to people's everyday life. For instance, proposals concerning migration policy are recently put to the vote almost every year in Switzerland. This explains for example, why citizens who participated in the vote on the popular initiative «Against mass immigration» ${ }^{22}$ were extremely well informed about the proposal: Milic (2015) finds that $90 \%$ voted in line with their true preferences, which is well above the average in his study. The different proposal issues are subsumed in the categories «institutions and fiscal policy», «immigration and foreign policy», «social policy and culture» and «environment».

\section{Multilevel Regression}

The data contains two levels of analysis: characteristics of individual respondents (level 1) and proposal specific factors (level 2). The estimated logistic regression models accommodate the hierarchical structure of the data by including both, level-1 and level-2 factors, and allowing intercepts to vary across proposals that cluster the observations in the data. Following the denomination in Steenbergen and Jones (2002), these models can be described using the following generalised equations.

Level-1 model equation:

$$
\mathrm{y}_{\mathrm{ij}}=\beta_{0 \mathrm{j}}+\beta_{1} \mathrm{x}_{1 \mathrm{j}}+\ldots+\beta_{\mathrm{n}} \mathrm{x}_{\mathrm{nj}}+\varepsilon_{\mathrm{i}}
$$

Level-2 model equation:

$$
\beta_{0 \mathrm{j}}=\gamma_{0}+\gamma_{1} \mathrm{z}_{1 \mathrm{j}}+\ldots+\gamma_{\mathrm{n}} \mathrm{z}_{\mathrm{nj}}+\delta_{\mathrm{j}}
$$

Multilevel equation:

$$
y_{i j}=\left(\gamma_{0}+\gamma_{1} z_{1 j}+\ldots+\gamma_{n} z_{n j}+\delta_{j}\right)+\beta_{1} x_{1 j}+\ldots+\beta_{n} x_{n j}+\varepsilon_{i}
$$

$\mathrm{y}_{\mathrm{ij}}$ is the dependent variable value consistent vote decision for level-1 unit «i» which is an individual voter. All level-1 units are nested in level-2 units denominated as «j». These are the different clusters that are constituted by proposals. Every «X» stands for a level-1 predictor. These include, depending on the regression model, education, proposal specific knowledge, political interest, identification with political party, adherence to party recommendation, the interaction between party adherence and education, ambivalence as well as gender and age as control variables. The regression coefficients of these independent variables on the individual level are denominated as $\left\langle\beta_{1}\right\rangle$ to $\left\langle\beta_{\mathrm{n}}\right\rangle$. $\left\langle\varepsilon_{\mathrm{i}}\right\rangle$ refers to the random errors of prediction for the level-1 equation. By letting model intercepts vary across level-2 units, the level-1 model parameter $\left\langle\beta_{0 j}\right\rangle$ does not yield a fixed effect. Instead, random effects of varying intercepts are calculated for each proposal. In fact, $\left\langle\beta_{0 j}\right\rangle$ varies as a function of level-2 factors. It predicts the average probability of casting a value consistent vote for each proposal in the analysis, depending on its proposal specific characteristics. In the level-2 model equation, all « $\gamma\rangle$-parameters denote the fixed level-2

\footnotetext{
${ }^{22}$ This initiative also figures in the data set for this study (see Table Al in the Online Appendix). The popular initiative «Against mass immigration» stems from the right-wing Swiss People's Party. It was put to the vote on 9 February 2014 and accepted by a slim majority of $50.3 \%$.
} 
Table 2: Results of Logistic Regression Models

\begin{tabular}{|c|c|c|c|c|c|c|}
\hline & Model 1 & Model 2 & Model 3 & Model 4 & Model 5 & Model 6 \\
\hline & $\begin{array}{l}\text { Sophistication \& } \\
\text { Identification }\end{array}$ & $\begin{array}{l}\text { Party } \\
\text { adherence }\end{array}$ & $\begin{array}{r}\text { Number of } \\
\text { proposals }\end{array}$ & $\begin{array}{l}\text { Camp } \\
\text { dominance }\end{array}$ & $\begin{array}{l}\text { Proposal } \\
\text { issue }\end{array}$ & $\begin{array}{l}\text { Full } \\
\text { model }\end{array}$ \\
\hline (Intercept) & $\begin{array}{l}1.288 * * * \\
(0.203)\end{array}$ & $\begin{array}{l}0.742^{* *} \\
(0.244)\end{array}$ & $\begin{array}{l}1.085^{* * *} \\
(0.289)\end{array}$ & $\begin{array}{l}0.744^{*} \\
(0.320)\end{array}$ & $\begin{array}{l}1.187 * * * \\
(0.142)\end{array}$ & $\begin{array}{l}1.941 * * * \\
(0.259)\end{array}$ \\
\hline Gender & $\begin{array}{l}0.096 \\
(0.055)\end{array}$ & $\begin{array}{l}0.135^{*} \\
(0.069)\end{array}$ & $\begin{array}{l}0.035 \\
(0.042)\end{array}$ & $\begin{array}{l}0.035 \\
(0.042)\end{array}$ & $\begin{array}{l}0.033 \\
(0.042)\end{array}$ & $\begin{array}{l}0.094 \\
(0.055)\end{array}$ \\
\hline Age & $\begin{array}{l}-0.003 \\
(0.002)\end{array}$ & $\begin{array}{l}-0.001 \\
(0.002)\end{array}$ & $\begin{array}{l}-0.004 * * \\
(0.001)\end{array}$ & $\begin{array}{l}-0.004 * * \\
(0.001)\end{array}$ & $\begin{array}{l}-0.004 * * \\
(0.001)\end{array}$ & $\begin{array}{l}-0.003 \\
(0.002)\end{array}$ \\
\hline $\begin{array}{l}\text { Education } \\
\text { «middle» } \\
\text { (Ref: education } \\
\text { «low») }\end{array}$ & $\begin{array}{l}0.123 \\
(0.071)\end{array}$ & $\begin{array}{l}-0.241 \\
(0.155)\end{array}$ & $\begin{array}{l}0.175^{* *} \\
(0.056)\end{array}$ & $\begin{array}{l}0.176^{* *} \\
(0.056)\end{array}$ & $\begin{array}{l}0.175^{* *} \\
(0.056)\end{array}$ & $\begin{array}{l}0.123 \\
(0.071)\end{array}$ \\
\hline $\begin{array}{l}\text { Education } \\
\text { «high» }\end{array}$ & $\begin{array}{l}0.314 * * * \\
(0.065)\end{array}$ & $\begin{array}{l}-0.468^{* *} \\
(0.142)\end{array}$ & $\begin{array}{l}0.414 * * * \\
(0.052)\end{array}$ & $\begin{array}{l}0.415 * * * \\
(0.052)\end{array}$ & $\begin{array}{l}0.410 * * * \\
(0.052)\end{array}$ & $\begin{array}{l}0.313 * * * \\
(0.065)\end{array}$ \\
\hline $\begin{array}{l}\text { Proposal } \\
\text { specific } \\
\text { knowledge } \\
\text { (dummy) }\end{array}$ & $\begin{array}{l}0.164 * * \\
(0.063)\end{array}$ & $\begin{array}{l}0.237 * * \\
(0.078)\end{array}$ & $\begin{array}{l}0.121^{*} \\
(0.049)\end{array}$ & $\begin{array}{l}0.125^{*} \\
(0.049)\end{array}$ & $\begin{array}{l}0.120^{*} \\
(0.049)\end{array}$ & $\begin{array}{l}0.145^{*} \\
(0.063)\end{array}$ \\
\hline Political interest & $\begin{array}{l}0.194 * * * \\
(0.041)\end{array}$ & $\begin{array}{l}0.131 * \\
(0.053)\end{array}$ & $\begin{array}{l}0.242 * * * \\
(0.030)\end{array}$ & $\begin{array}{l}0.242^{* * *} \\
(0.030)\end{array}$ & $\begin{array}{l}0.242 * * * \\
(0.030)\end{array}$ & $\begin{array}{l}0.196 * * * \\
(0.041)\end{array}$ \\
\hline $\begin{array}{l}\text { Identification } \\
\text { with political } \\
\text { party (dummy) }\end{array}$ & $\begin{array}{l}0.211^{* * *} \\
(0.063)\end{array}$ & & & & & $\begin{array}{l}0.212 * * * \\
(0.063)\end{array}$ \\
\hline $\begin{array}{l}\text { Adherence } \\
\text { to party } \\
\text { recommendation } \\
\text { (dummy) }\end{array}$ & & $\begin{array}{l}0.740 * * * \\
(0.107)\end{array}$ & & & & \\
\hline Interaction: & & $0.578 * *$ & & & & \\
\hline $\begin{array}{l}\text { Party adherence } \\
\text { * education } \\
\text { «middle» }\end{array}$ & & $(0.188)$ & & & & \\
\hline Interaction: & & $1.184 * * *$ & & & & \\
\hline $\begin{array}{l}\text { Party adherence } \\
\text { * education } \\
\text { «high» }\end{array}$ & & $(0.167)$ & & & & \\
\hline Ambivalence & $\begin{array}{l}-1.670^{* * *} \\
(0.341)\end{array}$ & $\begin{array}{l}-1.556^{* * *} \\
(0.424)\end{array}$ & & & & $\begin{array}{l}-1.642 * * * \\
(0.340)\end{array}$ \\
\hline Ambivalence $^{2}$ & $\begin{array}{l}0.229 \\
(0.313)\end{array}$ & $\begin{array}{l}0.422 \\
(0.395)\end{array}$ & & & & $\begin{array}{l}0.212 \\
(0.312)\end{array}$ \\
\hline $\begin{array}{l}\text { Number of } \\
\text { vote proposals }\end{array}$ & & & $\begin{array}{l}-0.151^{*} \\
(0.072)\end{array}$ & & & $\begin{array}{l}-0.067 \\
(0.051)\end{array}$ \\
\hline Camp dominance & & & & $\begin{array}{l}-0.258 \\
(0.423)\end{array}$ & & $\begin{array}{l}0.202 \\
(0.243)\end{array}$ \\
\hline $\begin{array}{l}\text { Issue: institutions } \\
\text { \& fiscal } \\
\text { policy (Ref: } \\
\text { immigration and } \\
\text { foreign policy) }\end{array}$ & & & & & $\begin{array}{l}-1.041^{* * *} \\
(0.189)\end{array}$ & $\begin{array}{l}-1.049 * * * \\
(0.186)\end{array}$ \\
\hline
\end{tabular}


Table 2: Continued

\begin{tabular}{lllllll}
\hline & Model 1 & Model 2 & Model 3 & Model 4 & Model 5 & Model 6 \\
\hline $\begin{array}{l}\text { Issue: social } \\
\text { policy }\end{array}$ & & & & & $-0.981^{* * *}$ & $-0.858^{* * *}$ \\
$\quad$ \& culture & & & & & $(0.188)$ & $(0.179)$ \\
$\quad \begin{array}{l}\text { Issue: } \\
\text { environment }\end{array}$ & & & & & $-1.255^{* * *}$ & $-1.121^{* * *}$ \\
AIC & 8780.749 & 5650.916 & 14115.051 & 14118.701 & 14090.263 & 8755.851 \\
BIC & 8858.283 & 5737.809 & 14182.412 & 14186.062 & 14172.594 & 8868.627 \\
$\begin{array}{l}\text { Log Likelihood } \\
\text { Num. obs. }\end{array}$ & -4379.375 & -2812.458 & -7048.526 & -7050.350 & -7034.132 & -4361.925 \\
$\quad \begin{array}{l}\text { Num. groups: } \\
\text { projet }\end{array}$ & 27 & 5908 & 13155 & 13155 & 13155 & 8506 \\
$\quad \begin{array}{l}\text { Var: projet } \\
\quad \text { Intercept) }\end{array}$ & 0.405 & 27 & 27 & 27 & 27 & 27 \\
$\begin{array}{l}\text { Intra-class } \\
\text { correlation }\end{array}$ & 0.11 & 0.338 & 0.360 & 0.415 & 0.112 & 0.090 \\
\hline
\end{tabular}

Notes: Table shows the effects of the individual-level and contextual-level factors on the dependent variable value consistent vote decision. The regression coefficients represent log-odds with standard errors reported in parentheses. Levels of statistical significance: ${ }^{* * *} \mathrm{p}<0.001,{ }^{* *} \mathrm{p}<0.01,{ }^{*} \mathrm{p}<0.05$

coefficients whereas every «Z» stands for a contextual-level control variable. These are the number of proposals that citizens need to vote on simultaneously, the indicator for camp dominance as well as the proposal issue. $\left\langle\delta_{\mathrm{j}}\right\rangle$ is a term that contains disturbances on level 2. Equations (1) and (2) presented above are subsumed and written as a single equation (3) that describes the fully specified hierarchical regression model.

\section{Results}

Different logit models were estimated to investigate to what extent the sophistication, identification and ambivalence hypotheses hold true empirically. ${ }^{23}$ Table 2 lists the regression coefficients for all predictors and their standard errors in parentheses. Models 1 and 2 do not contain any level-2 variables yet. In Models 3 to 5, proposal specific characteristics are individually added as control variables. Finally, Model 6 represents the fully specified model that contains all individual and contextual-level variables. ${ }^{24}$

In order to check whether the sophistication hypothesis holds true empirically, I describe the results obtained by the factors education, proposal specific knowledge and

\footnotetext{
${ }^{23}$ In addition, I ran probit regression models as a robustness check. All effects obtained by logistic regression were also found in the probit models that yielded the same significance levels for each regression coefficient. Furthermore, I also checked for possible cross-level interactions in multilevel regression models. For example, I assumed that the effects of the number of proposals and of the issue category (level 2) on value consistent voting is moderated by the level of proposal specific knowledge and education (level 1). However, there were no statistically significant cross-level interactions in any of the additionally estimated models.

${ }^{24}$ The question whether individuals are grouped by different proposals can be answered when looking at the variance in the dependent variable found on the proposal level and the intra-class correlation coefficients (ICC) for each model (cf. Table 2). Around 3 to $11 \%$ of the total variation in outcomes for value consistent voting can be explained by differences between proposals. Hence, there is some evidence that proposals form clusters of voters whose behaviour is more similar within the cluster than it is across them (see Online Appendix for a more detailed discussion of the ICC values).
} 
political interest in the following. In all computations, individuals with a low educational background serve as the reference category. Between them and people with a high education, a significant increase in the log-odds of casting a value consistent vote is reported. To make outcomes of logistic regression analysis more comprehensible I converted the log-odds into predicted probabilities. While holding all other model predictors constant, the chance that a citizen in the lowest education category votes according to his political core values is $76 \%$. If this voter was in the highest education category, he would have a probability of $82 \%$ to vote value consistently. This statistically significant increase in predicted probabilities between the lowest and highest education category is found in all regression models except for the interaction Model 2. This result is in line with hypothesis 1.1 postulating a higher probability to vote value consistently with increasing education.

Shedding light on the effect of proposal specific knowledge on value consistent voting, the results show that individuals who are capable of memorising both, title and content of a specific proposal, result in having a significantly higher chance to vote according to their basic political beliefs compared to ill-informed voters. Ceteris paribus, the difference in value consistent voting amounts to 3 percentage points between citizens exhibiting a low level of proposal specific knowledge and those in the higher knowledge category. All regression models suggest that hypothesis 1.2 stating the positive relationship between proposal specific knowledge and value consistent voting holds true.

Political interest significantly increases value consistent voting, too. As depicted in Figure 2, people with no political interest whatsoever attain a chance of $71 \%$ to vote value consistently. For people who are very interested in politics, the probability of casting a value consistent vote increases by 11 percentage points. In all models, the regression coefficients show that a one-unit increase in this indicator induces a statistically significant rise in the probability of value consistent voting. This result clearly supports the relationship between the independent and the dependent variable put forward in hypothesis 1.3. To sum up, there is strong empirical evidence that political sophistication plays a crucial role for people to vote in line with their basic political values.

Regarding the identification hypothesis, the results reveal that voters who identify with a political party have a significantly higher probability to cast a value consistent vote. The rise in value consistent voting amounts to 4 percentage points for party sympathisers compared to those who do not identify with a party. In Model 2, the effect of sticking to the preferred party's recommendation on value consistency was tested for those people who identify with a party. ${ }^{25}$ Indeed, corresponding to the recommendation significantly and strongly enhances value consistency in vote decisions. Party sympathisers who vote in line with their party have a chance of $84 \%$ to vote value consistently while this chance is 26 percentage points lower for those opposing their party. The obtained results lend support to the two identification hypotheses. However, since it remains unclear whether party sympathisers actually follow their preferred party's recommendation consciously, the results need to be interpreted with caution. Arguing that many voters most likely take their party's position into account at a sooner or later stage in their decision-making

\footnotetext{
25 Introducing the two dummies identification with political party and adherence to party recommendation into the regression model at the same time causes a multicollinearity problem. These two variables are perfectly correlated since the second dummy was computed using all respondents who identify with a political party. The two predictors thus need to be tested in different regression models.
} 
Figure 2: Predicted Probabilities of Value Consistent Voting for Different Levels of Political Interest

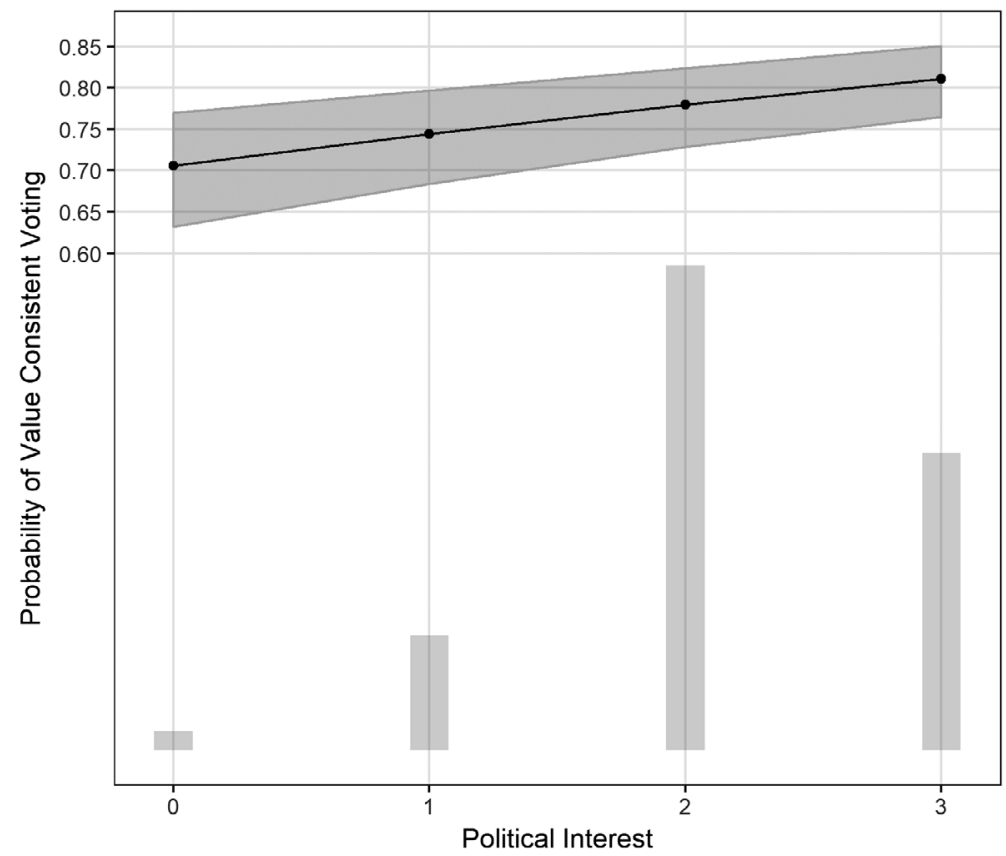

Notes: The shaded area represents the $95 \%$ confidence interval and the bars show the distribution of respondents according to their level of political interest.

process, the finding nevertheless lends support to the thesis that identification with a political party goes hand in hand with vote decisions being more value consistent.

In addition, the effect of corresponding to the preferred party's vote recommendation on value consistency is moderated by the level of education as postulated in the interaction hypothesis 2.3. To wit, the correlation coefficients of the interaction terms in Model 2 are positive and statistically significant. The predicted probabilities of a value consistent decision for adherence and non-adherence to the preferred party's recommendation are plotted across different education levels in Figure 3. The results reflect a clear pattern. For people with higher education, the effect of corresponding to the recommendation on value consistent voting is stronger than for lower educated citizens. Graphically, this finding is best visible when comparing the slopes for different education levels in Figure 3.

The higher the education level of voters, the steeper the slope. People in the highest education category thus benefit the most from following their party's vote recommendation if we assume that they do so actively.

Regarding the ambivalence hypothesis, the results in Models 1, 2 and 6 reveal a relatively strong and statistically significant negative effect of a growing ambivalence level on value consistency. Introducing the squared term of ambivalence into the regression model allows for checking whether there is a U-shaped relationship between ambivalence and value consistency. If this was the case, the squared term would yield a statistically significant positive regression coefficient. However, there is no evidence for the presumed relationship. The results emphasise that the higher someone scores on the ambivalence 
Figure 3: Predicted Probabilities of Value Consistent Voting for the Interaction «Party Adherence * Education»

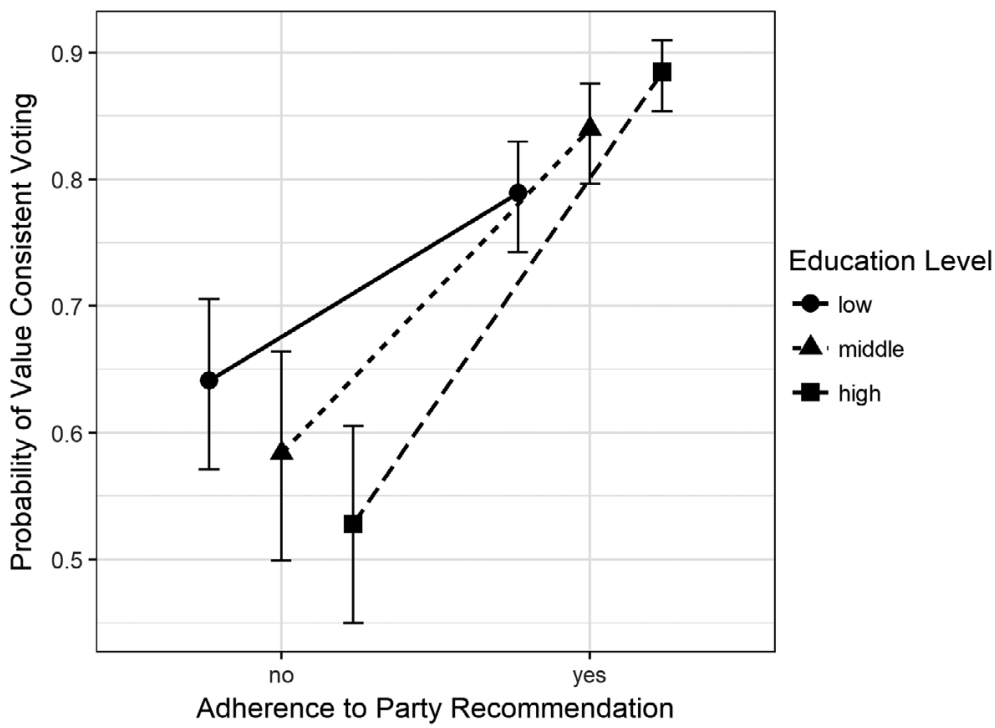

Note: The vertical lines represent the $95 \%$ confidence intervals.

Figure 4: Predicted Probabilities of Value Consistent Voting for Increasing Ambivalence

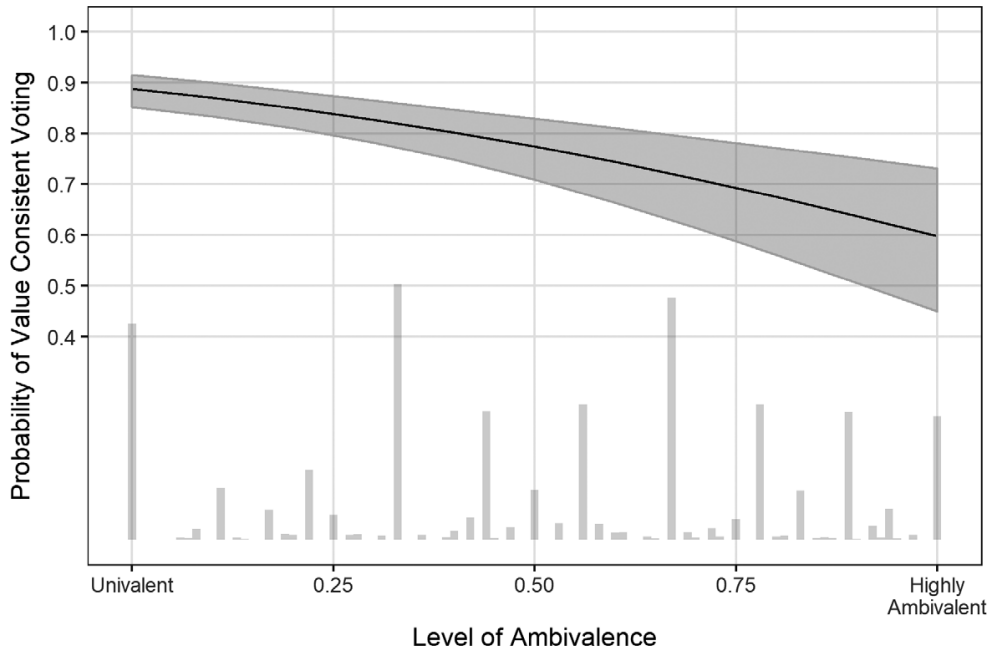

Notes: The shaded area represents the $95 \%$ confidence interval and the bars show the distribution of respondents according to their level of ambivalence.

index, the less he votes in line with political core values. Figure 4 demonstrates the drop in the probability of value consistent voting when comparing univalent voters to highly ambivalent ones based on Model 1. When holding all other model predictors constant, the predicted probability of value consistent voting shrinks from $89 \%$ to $60 \%$ for a full range increase in the independent variable ambivalence. 
The assumption made in hypothesis 3 that univalent and highly ambivalent voters stick to their basic political values equally strongly when deciding on vote proposals can be rejected. Evidently, highly ambivalent citizens do not rely upon their political core values when deciding in favour of or against proposals. They rather tend to vote against their basic values.

The control variables tested on the contextual level yield mixed results. The number of vote proposals has a significant negative effect on value consistent voting in Model 3. This effect disappears however in the fully specified model (cf. Model 6). Nevertheless, there seems to be at least a tendency that an increasing number of proposals lowers the probability to vote value consistently since the corresponding regression coefficient is negative. The level-2 variable camp dominance does not yield a statistically significant effect on value consistent voting whatsoever. Hence, an increasing dominance of one political camp over the other does not result in a smaller probability to cast a value consistent vote. In any case, these two contextual-level variables do not mitigate the results obtained for the proposed individual-level hypotheses and can thus be ruled out as possible confounders. However, the proposal issue obviously has a strong influence on value consistent voting. Compared to proposals about immigration and foreign policy, which serve as the reference category, proposals from the other issue categories «institutions and fiscal policy», «social policy and culture» and «environment» significantly

Figure 5: Predicted Probabilities of Value Consistent Voting for Different Issue Categories



Note: The vertical lines represent the $95 \%$ confidence intervals. 
reduce the probability to cast a value consistent vote. For a mean voter in the dataset, the probability of casting a vote that is in line with his basic political beliefs reaches the highest level $(86 \%)$ if the proposal is about immigration or foreign policy (cf. Figure 5). The same person has the lowest probability to vote value consistently if the proposal is about an environmental issue $(63 \%)$. If a proposal deals with «institutions and fiscal policy» or «social policy and culture», the chances of voting value consistently are $68 \%$ and $69 \%$, respectively.

Milic $(2012,2015)$ finds that the share of voters casting a correct vote in his definition is significantly higher when analysing proposals on immigration and contrasting them with other issue categories. The author argues that familiarity with the issue category serves as the main driver of his findings. The results presented in this paper show a similar outcome for value consistent voting. The question whether voters are indeed more familiar with issues on immigration and foreign policy cannot be answered conclusively. Besides familiarity, a possible explanation could be that the VOX questions that contain underlying political values for these issues («strong vs. no army», «open vs. isolated Switzerland» and «equal opportunities for Swiss citizens and foreigners») capture basic political values more adequately than those asked for other value dimensions. Or, people might have less ambiguous stances on questions concerning immigration and foreign policy since this topic has become omnipresent in the media.

Finally, the regression models uncover a somewhat unexpected outcome. The variable age, which was included as an individual-level control variable, reveals a negative effect on the probability to vote value consistently. In three models, this effect is significant on the $99 \%$ level (cf. Table 2). In general, younger citizens stick to their basic political values more often than older ones when casting a vote. It could be argued that older citizens are more used to the process of voting than their younger counterparts. Thanks to the older generation's greater experience with the political system it should rather be them who are more likely to cast votes that are in line with their political core values. However, this is not the case. Based on Model 3, the predicted probabilities for value consistent voting decrease by 5 percentage points between an 18-year-old and a 97-year-old voter, when holding everything else constant.

Previous empirical studies have detected a significant negative relationship between age and consistent and correct voting. Increasing age was associated with a lower probability of a correct vote in experimental studies about voters' information processing (Lau and Redlawsk 2006). In their study on correct voting in U.S. presidential elections, Lau et al. (2008) found that the oldest people in their sample were around 6\% less likely to vote correctly than 18-year-olds. In Switzerland, Milic (2012) also found a negative impact of increasing age on correct voting. In the case of the popular initiative banning the construction of minarets in 2009 , older people were significantly more likely to cast a vote that was not in line with their proposal-related arguments (Milic 2012). Lau and Redlawsk (2008) argued that age is strongly associated with declining cognitive abilities. The authors explicitly tested this explanation for the negative effect of increasing age on various dependent variables. They found strong empirical evidence that when people get older, they look for less information in political campaigns, they memorise less information and the information they memorise is less accurate (Lau and Redlawsk 2008). Moreover, older citizens have a significantly lower probability to vote correctly even when controlling for other predictors such as strength of party identification, political knowledge, number of prominent candidates running for office or party memories (Lau and Redlawsk 2008). Lau 
and Redlawsk (2008) find that this effect gets more pronounced especially from the age of 60 upwards.

Increasing age not only reduces the probability to vote correctly, but also the probability to vote in line with political core values. Beside the argument of decreasing cognitive abilities for older people, an alternative explanation might come into play. Compared to older citizens, younger generations could simply be more idealistic when casting a vote and thus stick to their basic political values more strongly. The former, knowing from their greater experience with the political system that ideologically radical proposals do usually not get through, might be more pragmatic in their vote decisions and deviate from their ideological standpoint more easily. In order to test the thesis that increasing age leads to a change in the mode of voting, namely from an idealistic to a more pragmatic way of decision-making, one would have to come up with a measure of how radical specific vote proposals are. ${ }^{26}$ If older people were indeed more pragmatic in their reasoning than younger voters, the former should tend to refuse proposals which are «too radical» more often. Generally, proposals that would bring about massive changes possibly lead to a less value consistent voting behaviour. Given the fact that Western populations increasingly grow older and that the quality of democratic decisions might under certain circumstances be endangered, further research on age effects on correct and (value) consistent voting is crucial.

\section{Conclusion}

The literature on correct and consistent voting behaviour has highlighted the importance of issue-opinions as well as argument-positions and based definitions of vote decisions that are in line with individual political preferences on these concepts. An often-neglected dimension of voting behaviour is the coherence of individual decisions with basic politic values. I argue that such values are more stable and less vulnerable to the impact of current events than political arguments or opinions. In theory, political core values build the fundament of political arguments and opinions. Proposing a novel measure of value consistent voting, this contribution expands theories on correct and consistent voting by investigating the consistency of vote decisions with basic political values.

Switzerland calls its citizens to the ballot boxes up to four times a year. People get to decide on a large number of different political issues ranging from flat-rate tax regimes for millionaires to imposing limits on immigration. Out of all vote decisions examined in this study, around a quarter was not in line with people's basic political values. Why do citizens jettison their moral concepts when they are asked to decide on concrete proposals? Based on dual models of opinion formation, this paper tests different approaches to explain value consistent voting behaviour, namely the sophistication, identification and ambivalence hypotheses.

The results lend strong support for the thesis that political sophistication serves as an important determinant of value consistency in vote decisions. People with lower levels of education, proposal specific knowledge and interest in politics vote against their basic values more often.

\footnotetext{
${ }^{26}$ The radicalness of proposals could, for example, be captured as a level-1 predictor measuring the individually perceived radicalness of a specific proposal or as a level-2 predictor which somehow accounts for the overall «objective» radicalness of different proposals. In the data used for this study, there was unfortunately no such measure.
} 
Voters who do not identify with a political party also result in having a higher probability to cast a value inconsistent vote. Among party sympathisers, the probability to vote against basic values is higher for those who do not stick to their party's recommendation compared to those who do. Because of the fact that it is impossible to derive from the data whether party sympathisers actively follow their preferred party's recommendation, caution is needed when interpreting these results. If people indeed use heuristics when deciding on how to vote, this means that especially the highly educated ones benefit from such a decision-making strategy. They reach a higher probability of value consistency in their decisions compared to less educated voters.

The assumption that univalent and highly ambivalent citizens vote along their basic political values to an equal extent does not hold true empirically. There is a distinct negative linear relationship between an increasing level of ambivalence towards a specific proposal and value consistent voting. The more ambivalent a person is, the less likely she votes in line with her political core values. In the setting of U.S. presidential elections, Lavine et al. (2012) argue that ambivalent voters do not reach decisions which are «inferior» to those made by univalent people. On the contrary, the authors find that highly ambivalent voters deal with alternatives more systematically, achieve higher levels of knowledge about the issues at stake and ultimately come to decisions of a higher quality as opposed to their univalent fellow citizens (Lavine et al. 2012). If one was to take consistency of individual vote decisions with basic political values as an indicator of their quality, the results of this paper rather join in with the literature that describes detrimental effects of ambivalence on individual voting behaviour (e.g., Basinger and Lavine 2005; Lavine 2001; McGraw et al. 2003). In the Swiss context, highly ambivalent voters decide against their basic political values significantly more often than univalent ones. Referring to Habermas' ideal democracy (1983) which includes the idea that citizens should be capable of voting according to their distinct beliefs and preferences, it can be argued that value inconsistent votes do not necessarily represent «high quality decisions».

Value consistent voting can be regarded as an expansion of theories and definitions of correct or consistent voting. If the quality of vote decisions does not only depend on issueopinions but also on the question whether citizens are capable of voting in line with their basic political values, then value consistent voting constitutes a key element for the wellfunctioning of a direct democracy. In view of some of the methodological shortfalls that both approaches bring about, future research is needed to combine existing measures of correct voting with value consistency in vote decisions and come up with further drivers of such a «high quality» voting behaviour.

\section{References}

Année Politique Suisse (APS) (2015). Basisdaten der Inserate zur eidgenössischen Abstimmung zur Volksinitiative "Millionen-Erbschaften besteuern für unsere AHV (Erbschaftssteuerreform)》 vom 14. Juni 2015. Année Politique Suisse, Institut für Politikwissenschaft der Universität Bern.

Année Politique Suisse (APS) (2016). Basisdaten der Inserate zur eidgenössischen Abstimmung «Bundesgesetz über den Strassentransitverkehr im Alpengebiet (Sanierung GotthardStrassentunnel)» vom 28. Februar 2016. Année Politique Suisse, Institut für Politikwissenschaft der Universität Bern.

Basinger, S. and H. G. Lavine (2005). Ambivalence, information, and electoral choice. American Political Science Review 99(2): 169-184. 
Bergbower, M. L., S. D. McClurg and T. Holbrook (2015). Presidential Campaign Spending and Correct Voting from 2000 to 2008. Social Science Quarterly 96(5): 1196-1213.

Bernhard, L. (2014). APS-Inserateanalyse der eidgenössischen Abstimmungen vom 28. September 2014. Bern: Institut für Politikwissenschaft der Universität Bern.

— (2015). APS-Inserateanalyse der eidgenössischen Abstimmungen vom 30. November 2014. Bern: Institut für Politikwissenschaft der Universität Bern.

Bühlmann, M. and M. Freitag (2006). Individual and contextual determinants of electoral participation. Swiss Political Science Review 12(4): 13-47.

Bundesamt für Statistik (BFS) (2018). Stimmbeteiligung. Online: https://www.bfs.admin.ch/bfs/de/ home/statistiken/politik/abstimmungen/stimm beteiligung.html [accessed: 07.12.2018].

Campbell, A., P. E. Converse, W. E. Miller and D. E. Stokes (1960). The American Voter. New York/London: University of Chicago Press.

Chen, P. Y. and P. M. Popovich (2002). Correlation: Parametric and nonparametric measures. Thousand Oaks, CA: Sage Publications.

Converse, P. E. (1964). The Nature of Belief Systems in Mass Publics. In Apter, D. E. (ed.), Ideology and Discontent. New York: The Free Press of Glencoe (206-261).

Dahl, R. A. (1989). Democracy and its critics. New Haven: Yale University Press.

Delli Carpini, M. and S. Keeter (1996). What Americans Know About Politics and Why It Matters. New Haven, CT: Yale University Press.

Frey, A. (2015). «Incorrect Voting» - Stimmt das Schweizer Stimmvolk nach eigenen Präferenzen? Eine empirische Analyse von «Incorrect Voting» anhand von zwei Volksinitiativen. Bachelorarbeit am Institut für Politikwissenschaft der Universität Zürich (IPZ).

Ha, S. E. and R. R. Lau (2015). Personality Traits and Correct Voting. American Politics Research 43(6): 975-998.

Habermas, J. (1983). Moralbewusstsein und kommunikatives Handeln. Frankfurt am Main: Suhrkamp.

Hadjar, A. and R. Becker. (2006). Politisches Interesse und politische Partizipation. In Hadjar, A. and R. Becker (eds.), Die Bildungsexpansion. Erwartete und unerwartete Folgen. Wiesbaden: VS Verlag für Sozialwissenschaften (179-204).

Holbrook, T. and S. D. McClurg. (2006). Campaign Effects and Correct Voting. Paper presented at the Annual Meeting of the Midwestern Political Science Association, Chicago, IL, April 2006.

Jerit, J., J. Barabas and T. Bolsen (2006). Citizens, Knowledge, and the Information Environment. American Journal of Political Science 50(2): 266-282.

Key, V. O. (1952). Politics, Parties and Pressure Groups. New York: Thomas Y. Crowell.

Kriesi, H., M. Brunner and F. Lorétan (2017). Standardisierte Umfragen VoxIt 1981-2016 [Dataset]. Université de Genève - Faculté des Sciences de la Société - SdS - Département de science politique et relations internationales, Universität Zürich - Philosophische Fakultät - Institut für Politikwissenschaft - IPZ - Lehrstuhl für Vergleichende Politikwissenschaft, FORS - Centre de compétences suisse en sciences sociales. Distributed by FORS, Lausanne. https://doi.org/10.23662/ FORS-DS-689-2 [accessed: 04.02.2020].

Lanz, S. and A. Nai (2015). Vote as you Think: Determinants of Consistent Decision Making in Direct Democracy. Swiss Political Science Review 21(2): 119-139.

Lau, R. R. and D. P. Redlawsk (1997). Voting correctly. American Political Science Review 91(3): $585-598$.

(2001). Advantages and Disadvantages of Cognitive Heuristics in Political Decision Making. American Journal of Political Science 45(4): 951-971.

(2006). How Voters Decide. Information Processing During Election Campaigns. Cambridge: Cambridge University Press. 
(2008). Older but Wiser? Effects of Age on Political Cognition. Journal of Politics 70(1): 168185.

(2015). The Effects of Advertising Tone on Information Processing and Vote Choice. In Nai, A. and A. S. Walter (eds.), New Perspectives on Negative Campaigning: Why Attack Politics Matters. Wivenhoe Park: ECPR Press Studies in European Political Science (249-266).

Lau, R. R., D. J. Andersen and D. P. Redlawsk (2008). An Exploration of Correct Voting in Recent U.S. Presidential Elections. American Journal of Political Science 52(2): 395-411.

Lau, R. R., P. Patel, D. F. Fahmy and R. R. Kaufman (2014). Correct Voting Across Thirty-Three Democracies: A Preliminary Analysis. British Journal of Political Science 44(2): 239-259.

Lau, R. R., R. A. Smith and S. T. Fiske (1991). Political Beliefs, Policy Interpretations, and Political Persuasion. Journal of Politics 53(3): 644-675.

Lavine, H. G. (2001). The electoral consequence of ambivalence toward presidential candidates. American Journal of Political Science 45(4): 915-929.

Lavine, H. G., C. D. Johnston and M. R. Steenbergen (2012). The Ambivalent Partisan: How Loyalty Promotes Democracy. New York: Oxford University Press.

Lupia, A. (1994). Shortcuts versus Encyclopedias: Information and Voting Behavior in California Insurance Reform Elections. American Political Science Review 88(1): 63-76.

McGraw, K., N. Pinney, E. Hanseke and K. Conger (2003). Ambivalence, uncertainty, and processes of candidate evaluation. Political Psychology 24(3): 421-448.

Milic, T. (2008). Ideologie und Stimmverhalten. Zürich: Rüegger. (2010). Steuern die Parteien das Volk? Der Einfluss der Parteien auf die inhaltliche Argumentation ihrer Anhängerschaften bei Schweizer Sachabstimmungen. Zeitschrift für Politikwissenschaft 20(1): 3-45.

— (2012). Correct Voting in Direct Legislation. Swiss Political Science Review 18(4): 399-427. (2015). «For They Knew What They Did» - What Swiss Voters Did (Not) Know About the Mass Immigration Initiative. Swiss Political Science Review 21(1): 48-62.

Milic, T., B. Rousselot and A. Vatter (2014). Handbuch der Abstimmungsforschung. Zürich: Verlag Neue Zürcher Zeitung.

Nai, A. (2009). Explaining correct voting in Swiss direct democracy. APSA 2009 Toronto Meeting Paper.

(2014). The Cadillac, the mother-in-law, and the ballot: individual and contextual roots of ambivalence in Swiss direct democracy. Electoral Studies 33: 292-306.

(2015). The Maze and the Mirror: Voting Correctly in Direct Democracy. Social Science Quarterly 96(2): 465-486.

Rosenberg, S. W. (2015). Theory of Opinion Formation. In Wright, J. D. (ed.), International Encyclopedia of the Social \& Behavioral Sciences (Second Edition). Oxford: Elsevier (243-245).

Sabatier, P. A. and C. M. Weible (2007). The Advocacy Coalition Framework: Innovations and Clarifications. In Sabatier, P. A. (ed.), Theories of the Policy Process. Boulder CO: Westview (189-220).

Simon, H. A. (1957). Models of Man. New York: Wiley.

Schwartz, S. H. and W. Bilsky (1987). Toward a universal psychological structure of human values. Journal of Personality and Social Psychology 53(3): 550-562.

Sniderman, P. M., R. A. Brody and P. E. Tetlock (1991). Reasoning and Choice: Explorations in Political Psychology. New York: Cambridge University Press.

Sokhey, A. E. and S. D. McClurg (2012). Social Networks and Correct Voting. The Journal of Politics 74(3): 751-764.

Steenbergen, M. and B. Jones (2002). Modeling Multilevel Data Structures. American Journal of Political Science 46(1): 218-237. 
Verba, S. and N. H. Nie (1972). Participation in America: Political Democracy and Social Equality. New York: Harper and Row.

Verba, S., N. H. Nie and J.-O. Kim (1978). Participation and Political Equality. A seven-nation comparison. Cambridge: Cambridge University Press.

Zaller, J. (1992). The Nature and Origins of Mass Opinion. Cambridge: Cambridge University Press.

\section{Supporting Information}

Additional Supporting Information may be found in the online version of this article: Supplementary Material

Lukas Lauener is Researcher at the Swiss Centre of Expertise in the Social Sciences (FORS) and a PhD student at the University of Lausanne. His research interests lie in voting behaviour, party systems, and the bilateral relations between Switzerland and the European Union. E-mail: lukas.lauener@fors.unil.ch. 